\title{
ARTISTAS VIAJANTES NAS FRONTEIRAS DA HISTÓRIA DA ARTE
}

\author{
Claudia Valladão de Mattos \\ Instituto de Artes-Unicamp
}

O "artista viajante" é um conceito estabelecido na historiografia da arte sobre o século XIX no Brasil. Existe uma bibliografia abundante sobre o tema e ele é tão familiar que deixamos de nos perguntar a respeito de seu estatuto e de sua função na construção do discurso teórico sobre a arte daquele período. Neste trabalho gostaria de desenvolver algumas reflexões sobre o conceito de "artista viajante", avaliando sua relevância teórica e discutindo seu papel no contexto do desenvolvimento da história da arte.

Comecemos com algumas observações simples: apesar do termo "artista viajante" parecer explicar-se por si mesmo - pois viajante é simplesmente aquele que viaja - rapidamente nos damos conta que esta definição não é suficiente, já que, ao longo de diferentes períodos da história, um número significativo de artistas que viajaram não foi contemplado sob esse conceito. Sabemos que ao menos desde o século XVI viagens se tornaram parte importante da carreira de muitos artistas na Europa. No século XVIII, elas passaram a ser imprescindíveis para a formação artística. O Grand Tour, praticado por jovens nobres como forma de adquirir uma formação (Bildung), tornou-se também oportunidade para muitos artistas sem grandes recursos próprios viajarem no papel de acompanhantes, aproveitando para formar seu olhar. Outros artistas do período circulavam pelas cortes européias, seguindo uma tradição já bem estabelecida na Europa desde ao menos o Renascimento. Logo percebemos que o conceito de "viajante" aplica-se apenas àqueles artistas que se aventuraram por lugares distantes, localizados para além das fronteiras da própria Europa.

O conceito de "artista viajante" nasceu, de acordo com Dawn Ades, associado a outro termo cunhado no final do século XVIII e popularizado através da obra de William Gilpin: o pitoresco. Em seu Three Essays" ${ }^{\prime}$, mais especialmente, em seu On picturesque travel o autor analisa o prazer que advém das viagens, aparentemente realizadas sem um objetivo definido, argumentando que o fim das mesmas seria a busca pelo pitoresco.

1 William Gilpin, Three Essays: on Picturesque Beauty, On Picturesque Travel, and on Skeching Landscape, London, 1794. 
No texto, o termo é então definido como uma terceira categoria estética, ao lado do sublime e do belo, e relacionado à natureza, principalmente em sua forma inexplorada. Diz o autor: "A principal fonte de entretenimento do viajante pitoresco é a perseguição de seu objetivo - a expectativa de novas cenas se abrindo e revelando-se à sua visão. Pressupomos que a região seja inexplorada. Sob tais circunstâncias, a mente é mantida num estado constante de agradável suspense. $\mathrm{O}$ amor pela novidade é o fundamento desse prazer. Todo horizonte distante promete algo de novo, e com essa agradável expectativa nós seguimos a natureza através e todas as suas andanças. A seguimos dos morros aos vales, e caçamos aquelas belezas variadas que abundam nela em toda parte."2

Lendo o livro de Gilpin, não é difícil compreender como a produção de artistas realizada em "partes distantes do planeta", veio a ser analisada, na Europa, sob a chave do pitoresco. A falta de conhecimento quase total a respeito da natureza e da cultura das Américas, a novidade das cenas naturais e humanas retratadas por artistas que lá estiveram, pareciam corresponder plenamente à categoria proposta por Gilpin. Do ponto de vista do público consumidor dessas imagens, no entanto, não interessava $\mathrm{o}$ processo envolvido em sua construção, assim como não interessava a formação do artista (ou amador) que realizou a imagem. A imagem, reduzida à documentação de um trecho novo do planeta funcionava para o observador como a própria natureza, provocando o sentimento do pitoresco, ao mesmo tempo em que, como analisa Tom Mitchell em seu livro Landscape and Power, podia servir no processo político de domesticação das regiões colonizadas do globo ${ }^{3}$.

A questão que nos interessa, no entanto, é como e porque essa categoria, nascida no final do século XVIII como forma de atribuir uma dimensão estética às novas imagens produzidas no contexto da expansão dos limites da cultura Européia terminou sendo adotada como uma categoria operante no contexto da disciplina da história da arte.

A dimensão geográfica do conceito parece ter certa importância. Thomas DaCosta Kaufmann, que em seu livro Towards a Geography of Art, analisa as relações entre conceitos geográficos e a formação da disciplina de história da arte, argumenta que desde suas origens mais remotas a disciplina manteve uma forte dependência de conceitos geográficos. Desde a

${ }^{2}$ Idem, Essay II, p. 47.

${ }^{3}$ WJT Mitchell (org.), Landscape and Power, Chicago e Londres: Chicago University Press, $2^{\mathrm{a}}$ ed., 2004. 
Antiguidade clássica, essa estreita relação entre arte e geografia já estava estabelecida. Vitrúvio, por exemplo, relacionava os edifícios aos lugares onde eram construídos e, como vários outros autores, associava as diferenças encontradas no âmbito das edificações às suas localizações geográficas e climáticas. Também Plínio, ao discutir a produção artística numa relação direta com os materiais dos quais eram feitos, estabelecia um vínculo estreito entre arte e condições geográficas. Tal vínculo reaparece na obra de Vasari, que discute as biografias dos artistas numa estreita relação com as cidades italianas, além de estabelecer uma ligação implícita entre localidade e maneira, especialmente em seu argumento sobre o colorido veneziano e o disegno florentino. No século XVIII, Winckelmann situa o argumento da influência do local e do clima sobre a obra de arte no centro de sua discussão, abrindo caminho para a idéia (romântica) de uma ligação entre arte e caráter nacional que, associado à idéia de "escola pictórica" teorizada por Luigi Lanzi (1792), transformou as narrativas da história da arte em uma espécie de jogo das diferenças entre a produção de diversos territórios europeus. Assim, já no final do século XIX, no momento da institucionalização da disciplina, Heinrich Wölfflin cunharia o conceito de "Dürerzeit" para designar o período do renascimento no norte da Europa, em oposição ao renascimento italiano e Worringer, inspirado em Wölfflin e Riegl, oporia o "caráter nórdico" ao "caráter mediterrâneo", em seu Abstraktion und Einfublung (1908). Essa instrumentalização de conceitos geográficos no contexto da análise de obras de arte levou à construção de um mapa que punha em relação toda a história da arte européia. Os limites da disciplina tornaram-se, assim, implicitamente, também limites geográficos. Para além desses limites, silenciava-se o discurso competente do historiador da arte. Para lidar com a produção iconográfica estabelecida para além dessas fronteiras, adotou-se o conceito de "artistas viajantes", um conceito que passou a operar, portanto, nas fronteiras da história da arte.

A primeira característica inerente ao modus operandi desse conceito é que à diferença do discurso sobre a arte na Europa, suprime-se em grande parte uma análise formal das obras e sua relação com as diferentes tradições artísticas européias. Como conseqüência, sob a categoria de "artistas viajantes" passa a caber não só artistas, mas todos aqueles que, por um motivo ou outro, produziram imagens sobre locais distantes. De uma forma geral, a bibliografia sobre "artistas viajantes" não se concentra no contexto específico e nas condições reais que geraram a produção de imagens, mas diante dessa produção desenvolve-se um discurso abstrato sobre o próprio olhar europeu, tateando os próprios limites de seu discurso. 
Assim, uma boa parte da bibliografia sobre "viajantes" dedica-se à análise do "olhar britânico", do "olhar alemão", do "olhar francês", etc. sobre os territórios e os povos dos novos continentes. Esse discurso reflexivo evidencia o desconhecimento quase completo das condições reais de produção artística nos territórios não europeus, apontando para a necessidade do estabelecimento de novas teorias e métodos capazes de expandir as fronteiras da disciplina para permitir a inclusão desta produção no main stream da reflexão sobre arte. A revisão crítica do modus operandi tradicional da disciplina tem se tornado uma preocupação central de muitos historiadores da arte, como Tom Mitchell, James Elkins, Michael Ann Holly, ou Kaith Moxey, que se dedicam a inventar a possibilidade de uma história da arte global (este foi inclusive o tema de uma das sessões do último congresso do Comitê Internacional de História da Arte, ocorrido em Melbourne).

Posto nas fronteiras da história da arte, o conceito de "artista viajante" mostrou-se de fato inoperante. Associado ao conceito de pitoresco, ele tende a reduzir o não europeu a um "outro" genérico, impossibilitando a análise das condições efetivas da construção de determinadas imagens e de seus usos nas relações de poder. Como demonstrarei a seguir, ele é um conceito que impede a compreensão da diversidade da produção desses artistas (e não artistas) e funciona antes como uma forma de resistência ao projeto de construção de uma história da arte global, isenta dos preconceitos que acompanharam o surgimento e desenvolvimento da disciplina desde o século XIX.

A seguir darei alguns exemplos de abordagens alternativas à produção desses "viajantes", que se mostram muito mais produtivas, tanto no que diz respeito à produção de conhecimento sobre essas imagens, quanto à sua colaboração para a construção de um discurso menos eurocêntrico no campo da história da arte.

Antes, porém, gostaria de comentar ainda a surpreendente popularidade que o conceito de "artista viajante" conquistou na historiografia da arte brasileira. Entre nós, não só existe uma bibliografia extensa sobre o tema, como encontramos uma série de coleções que se estruturam a partir desse conceito, como a coleção da Fundação Estudar, incorporada recentemente à Pinacoteca de São Paulo, a coleção Mindlin e a da família Stickel, por exemplo. Tanto na literatura sobre o tema, quanto na organização dessas coleções, notamos uma tendência marcante a contrapor o "olhar estrangeiro" do viajante ao "nosso olhar", revelando claramente que por trás do interesse pela produção dos viajantes encontra-se um desejo 
de construir uma identidade "nossa" em oposição à identidade "deles". De instaurar um "olhar nosso", em oposição ao "olhar distante deles" (não por acaso Olhar Distante foi o nome encontrado para a sessão sobre "viajantes" durante a Mostra do Redescobrimento). Nesse jogo, novamente uma concepção de vôo de pássaro substitui a investigação minuciosa das circunstâncias da produção dessas imagens e nos perdemos no acúmulo visual das imagens (em geral deslocadas do seu real contexto de produção) à busca de uma "identidade nacional".

Mas passemos aos exemplos, que demonstram que, nos últimos anos, ao lado dos ainda freqüentes discursos sobre o "olhar" dos "viajantes", começamos a ver nascer a possibilidade de utilizar os instrumentos próprios da disciplina para abordar a produção iconográfica de artistas europeus no Brasil, ajudando a expandir as fronteiras da própria História da Arte.

O primeiro exemplo que gostaria de analisar é o de Jean-Baptiste Debret. Talvez mais que qualquer outro "viajante", Debret é em geral considerado um artista especialmente relevante para a construção de nossa identidade nacional. A maior parte da bibliografia sobre Debret vê sua produção em primeiro lugar como um documento "fiel" à realidade do país no século XIX. No catálogo da coleção Castro Maya, lançado recentemente, Julio Bandeira escreve, por exemplo, que "Jean-Baptiste Debret foi, de todos os seus contemporâneos, o único artista viajante a penetrar na velada intimidade brasileira (...)", qualificando-o de "artista atemporal", cujas "imagens conseguiram conservar aberta uma janela para o mundo colonial ao mesmo tempo em que um país ainda inocente da cultura européia aburguesada perdia-se na busca de uma nova identidade ocidental"4. Essa imagem de Debret como viajante e fiel cronista da realidade brasileira do século XIX apresenta, no entanto, problemas evidentes. Debert morou 16 anos no Brasil e como bem afirma Valéria Lima em seu livro sobre o artista, ele "vem para o Brasil para informá-lo e não para informar-se" ao integrar-se à Missão Francesa ${ }^{5}$. Já por isso, a categoria de viajante, com os pressupostos correlatos de observação e registro do pitoresco (que estão por trás de argumentos como os de Bandeira) deve ser questionada. A idéia de uma fidelidade dessas imagens

\footnotetext{
${ }^{4}$ Julio Bandeira, "Janelas d'alma brasileira", in: Castro Maya Colecionador de De Bret, Rio de Janeiro: Cpivara, 2003, p. 44.

${ }^{5}$ Valéria Lima, J.-B. Debret Historiador e Pintor, Campinas: Editora da Unicamp, 2007, p. 176.
} 
ao "real" também não se sustenta diante da evidência da reutilização que Debret faz, em seu livro, de desenhos de outros artistas, como Rugendas, e do fato dele representar lugares e cenas que certamente não pôde vivenciar de primeira mão (especialmente as cenas envolvendo indígenas).

O pesquisador sente-se também compelido a explicar, por exemplo, como a imagem de um Debret "viajante", preocupado, como se supõe, com o registro fiel da realidade, pode conciliar-se com sua formação neoclássica de pintor histórico.

Pesquisas recentes têm demonstrado que não basta qualificar a produção de Debret com os termos "neoclássico", ou "pintor de história", ou "viajante". A interpretação da produção do artista depende de uma compreensão mais precisa sobre sua inserção no contexto brasileiro, assim como de uma avaliação dos modos com que o artista opera algumas categorias fundamentais da tradição artística, num momento em que tais categorias encontram-se em franca transformação. É importante reconhecer, por exemplo, que Debret dialoga com duas tradições diferentes ao trabalhar para a corte como pintor de História e ao escrever a Viagem, texto esse vinculado à longa tradição da literatura de viagem; mas é igualmente necessário reconhecer a aproximação que Debret promove entre os dois gêneros ao realizar quadros de história de pequenas dimensões destinados à reprodução litográfica, como afirma Luciano Migliaccio $^{6}$. O resgate de documentos que testemunham as atividades de Debret no Brasil e na Europa, como vem sendo realizado por pesquisadores como Valéria Lima e Elaine Dias, entre outros, são ainda de imprescindível ajuda para construir um quadro mais exato da produção do artista no Brasil. Diante desse quadro, certamente perceberemos o pouco alcance que a chave interpretativa vinculada ao conceito de viajante oferece.

Gostaria a seguir de discutir brevemente o conceito de "artista viajante" relacionado-o à obra de artistas que, de fato, estiveram viajando pelo Brasil, ligados a expedições científicas, como foi o caso de Thomas Ender, Johann Moritz Rugendas, ou Hercules Florence. Seria produtivo considerar a obra desses artistas sob a chave dos "viajantes"? Como vimos, o conceito encerra a idéia de um registro objetivo da natureza pitoresca dos trópicos. Ao abordarmos as produções desses artistas, portanto, tendemos a tratá-la antes de tudo como documento, pensando-as fora do contexto da

${ }^{6}$ Luciano Migliaccio, "O Século XIX”, in: Catálogo da Mostra do Redescobrimento, São Paulo: Fundação Bienal, 2000. 
história da arte, isto é, sem levar em conta o seu estatuto de imagem (exatamente esse efeito, como vimos, é próprio à posição do conceito de "viajante" com relação à história da arte tradicional). Indício desse tratamento é a tendência a não discriminar a produção de "artistas viajantes" daquela de outros "viajantes", naturalistas, militares, diletantes, etc. Também não nos preocupamos em compreender essas imagens como negociadas em um contexto específico, isto é, esquecemos que, em sua maior parte, elas foram encomendadas e não espelham diretamente, ou unicamente o projeto do artista. O discurso sobre os "viajantes" desvia ainda o pesquisador da necessidade de compreender a inserção real de cada um desses artistas, compreender as negociações e os intercâmbios próprios a tais viagens. Faltam ainda estudos sobre a importância das diferentes teorias sobre paisagem, como as do próprio Gilpin, ou de Humboldt, por exemplo, sobre essa produção. O conceito de "artista viajante" tende a nos desviar desses caminhos. Gostaria de comparar apenas duas imagens, de temas semelhantes, para argumentar visualmente sobre a importância dessas reflexões. A primeira é uma gravura de Johann Moritz Rugendas, intitulada "Ponte de Cipó", que ilustra seu livro Viagem Pitoresca Através do Brasil, publicado em 1835 (fig. 1). Aqui podemos ver como o artista apresenta uma síntese das atividades indígenas e de sua relação de intimidade e dependência da floresta, à maneira de Humboldt. A composição é pensada de forma a apresentar clara e didaticamente uma série de atividades que, certamente, não ocorriam ao mesmo tempo: a caça com arco e flecha, o transporte das crianças, a construção de pontes, a extração de alimentos, a construção de habitações, entre outros. Também a floresta é concebida de forma sintética, procurando transmitir um "quadro (Ansicht) da natureza" local, mais do que representar, de forma fiel, a vegetação específica de um determinado lugar. A cena é cuidadosamente composta. Duas massas de árvores nativas emolduram as figuras centrais, organizadas em um círculo quase perfeito ao centro. Por trás delas, a vista estende-se em direção à amplidão da floresta, mediada pela presença de um caudaloso rio. O ponto de vista elevado acentua essa qualidade sintética e composta da imagem. As figuras são características (também no sentido de Humboldt). Representam tipos indígenas, mas sem a preocupação de realizar deles um retrato.

A segunda imagem é uma aquarela realizada por Hercules Florence durante a expedição Langsdorff, da qual participou entre 1825 e 1829 (fig. 2). Aqui a intenção também era a de registrar os índios brasileiros e seu ambiente, mas o artista realiza a tarefa de forma muito diferente. Ao invés 
da composição sintética de Rugendas, nos vemos diante de uma série de índios que nos olham, como em uma fotografia (é mesmo possível que Florence tenha usado uma câmara clara para captação da imagem). No lugar do ponto de vista elevado adotado por Rugendas, estamos agora face a face com esses indivíduos que parecem posar para o artista. Como em uma fotografia, ao olhar a imagem, ocupamos o lugar do artista e entramos em comunicação direta com as figuras representadas. Por trás do grupo em primeiro plano, e à direita, em plano médio, vemos uma série de índios em suas atividades cotidianas, porém sem o caráter tipológico das figuras de Rugendas.

Tanto Rugendas, quanto Florence, tinham como objetivo "registrar a realidade brasileira" e ambos fizeram parte da mesma expedição. No entanto, as estratégias e os recursos utilizados para tal fim foram muito diferentes. Investigar os contextos específicos que resultaram nessas diferentes imagens deveria ser a preocupação central do historiador da arte.

Precisamos com urgência colocar os instrumentos da história da arte, da análise própria ao campo das imagens, a serviço do estudo da produção de artistas estrangeiros que retrataram o Brasil. Para isso, faz-se necessário reconhecer a diversidade dos projetos, das formas de inserção e das abordagens dos assim chamados "viajantes" e nos desvencilharmos de um conceito que, como esperamos ter demonstrado, trabalha contra a possibilidade de expandirmos as fronteiras da disciplina e trabalharmos com a perspectiva promissora de uma história da arte inclusiva. 

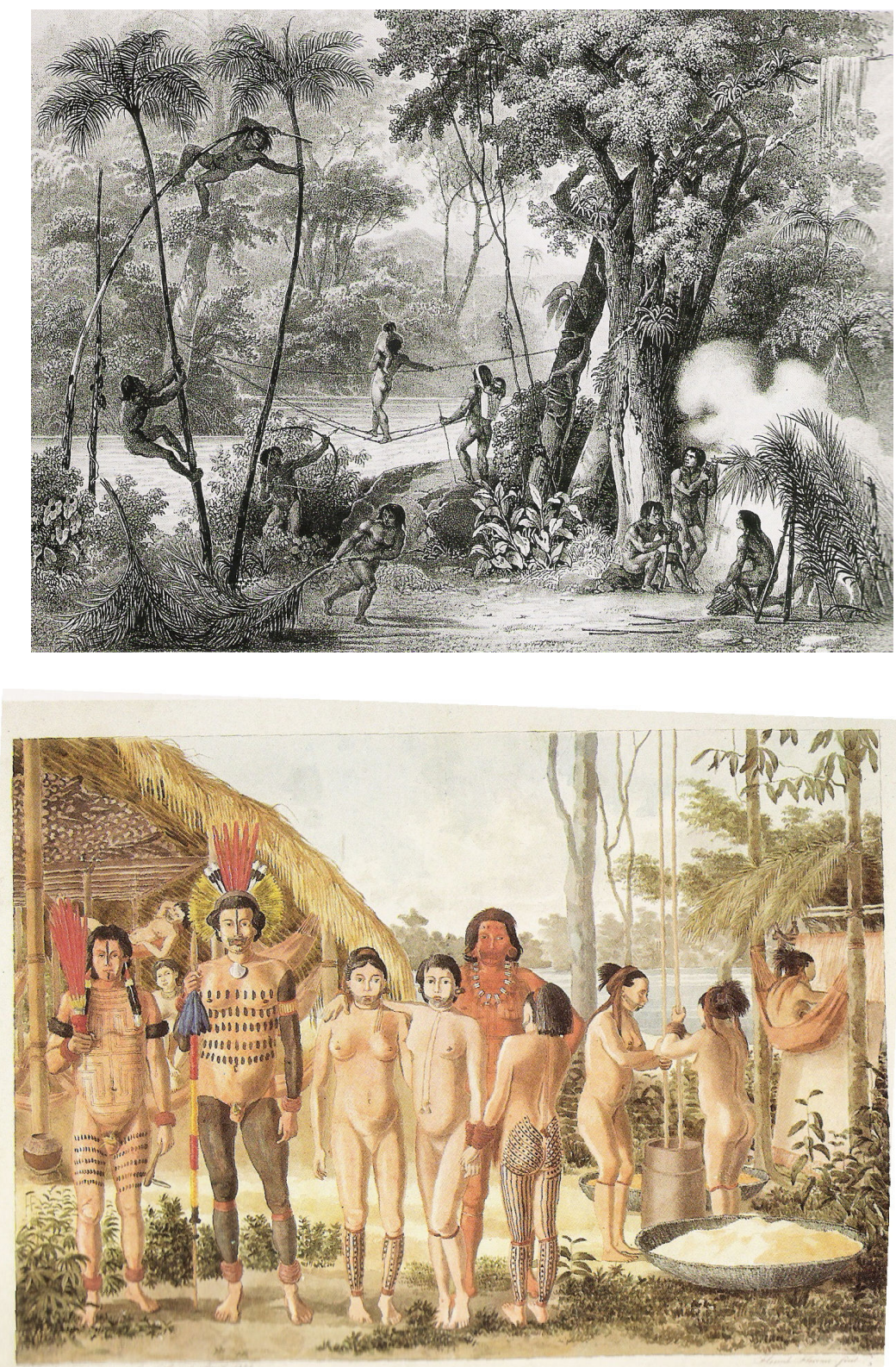